\title{
ACCESO A LA INFORMACIÓN Y PROTECCIÓN DE DATOS EN MÉXICO EN TIEMPOS DE LA PANDEMIA. ¿QUÉ ESPERAR DE UN GOBIERNO ABIERTO Y RESPONSABLE?
}

\author{
ACCESS TO INFORMATION AND DATA PROTECTION IN \\ MEXICO IN TIMES OF THE PANDEMIC. WHAT TO EXPECT \\ FROM AN OPEN AND RESPONSIBLE GOVERNMENT?
}

\author{
Ana CRistina GonzÁLEz Rincón* \\ IIJ-UNAM, México \\ anacristina.glzr@gmail.com
}

\section{RESUMEN:}

El acceso a la información pública y la protección de datos personales son derechos reconocidos en la Constitución mexicana, los cuales cobran mayor relevancia en época de la pandemia. El Estado debe ser claro en las medidas políticas, económicas, jurídicas y de otra índole que se están tomando para contener la enfermedad, pero esa claridad solo es una parte del acceso a la información, pues es necesario también que los ciudadanos conozcan los hechos reales y el calendario para regresar a la nueva normalidad. La protección de datos implica, por su parte, que se respete la recolección de información personal durante la pandemia y que ésta cumpla con los principios establecidos por las leyes.

\section{Palabras clave:}

Derecho de acceso a la información, protección de datos personales, INAI, pandemia covid-19, gobierno abierto.

\section{ABSTRACT:}

Access to public information and the protection of personal data are both rights recognized in the Mexican Constitution, which become more relevant at the time

* Estudiante de doctorado en derecho en el IIJ-UNAM. 
of the pandemic. The State must be clear in the political, economic, legal and other measures that are being taken to contain the disease, but that clarity is only one part of the access to information, since it is also necessary for citizens to know the real facts and the timetable to return to the new normal. Data protection implies, for its part, that the collection of personal information during the pandemic is respected and that it complies with the principles established by law.

\section{Keywords:}

Right of access to information, protection of personal data, INAI, covid-19 pandemic, open government.

SUMARIO: I. Introducción; II. La importancia de un gobierno abierto y responsable en época de la pandemia y su vigilancia por un órgano autónomo; III. Otros sectores que deben ser protegidos durante la pandemia; IV. Retos actuales del acceso a la información y protección de datos en la pandemia; V. Conclusiones; VI. Bibliografía.

\section{INTRODUCCIÓN}

El 30 de enero de 2020 la enfermedad por coronavirus COVID-19 causada por el virus SARS-COV-2 fue declarada por la Organización Mundial de la Salud (OMS) como una Emergencia de Salud Pública de Importancia Internacional. El 11 de marzo del mismo año, la OMS la declaró como pandemia y, a partir de esa fecha, los diversos países en el mundo se han tenido que movilizar ante la amenaza de propagación y con el objetivo de disminuir el nivel de riesgo y contagio al interior de sus territorios.

En el caso de México, el 30 de marzo el Consejo de Salubridad General (CSG) reconoció que el número de casos había ido en aumento, por lo que declaró como emergencia sanitaria por causa de fuerza mayor a la epidemia, recomendando que los habitantes del país permanecieran en sus casas para contener la enfermedad. ${ }^{1}$ El 31 de marzo, la Secretaría de Salud publicó el Acuerdo ${ }^{2}$ con nuevas medidas de seguridad sanitaria entre las que se destacaron la suspensión inmediata del 30 de marzo al 30 de abril de actividades no esenciales en los sectores público, privado y social con la finalidad de mitigar la dispersión y transmisión del virus en la comunidad. En los sectores y actividades definidos como esenciales, ${ }^{3}$ se aplicaron de manera obligatoria acciones como no realizar reuniones o congregaciones de más de 50 personas, lavado frecuente de manos, estornudar o toser aplicando la etiqueta respiratoria, saludo a distancia, entre otras. Se aplicó también el resguardo domiciliario a toda persona mayor de 60 años o con

\footnotetext{
Véase https://dof.gob.mx/2020/CSG/CSG_300320_VES.pdf

Véase http://dof.gob.mx/nota_detalle.php? codigo $=5590914 \&$ fecha $=31 / 03 / 2020$

3 Se consideran cinco categorías como actividades esenciales: a) Las necesarias para atender la emergencia sanitaria (rama médica, paramédica, administrativa y de apoyo en todo el sector salud, público y privado); b) Seguridad pública y la protección ciudadana (defensa y soberanía nacional, procuración e impartición de justicia y actividad legislativa); c) Sectores considerados como esenciales para el funcionamiento fundamental de la economía; d) Los necesarios para la operación de los programas sociales del gobierno; y e) Los de conservación y mantenimiento de infraestructura crítica que asegura la producción y distribución de servicios indispensables. Véase http://dof.gob.mx/nota_detalle.php?codigo=5590914\&fecha=31/03/2020
} 
alguna enfermedad crónica independientemente de si su actividad fuera considerada esencial. Siguiendo las declaratorias anteriores, diversos entes públicos empezaron a tomar medidas, como es el caso de la Secretaría de Educación Pública, la que implementó un receso escolar que en principio comprendía del lunes 23 de marzo al viernes 17 de abril, reanudando labores el lunes 20 de abril en cada plantel escolar, siempre que se contara con las condiciones determinadas por la autoridad sanitaria. ${ }^{4}$ Otros poderes como el judicial federal y algunos órganos constitucionales autónomos como el Instituto Nacional de Acceso a la Información y Protección de Datos (INAI) ${ }^{5}$ también decidieron suspender provisionalmente sus labores en atención a la emergencia sanitaria con el fin de disminuir al máximo la posibilidad de contagio entre las personas.

En este contexto llama la atención dos cosas. En primer lugar, sobre la circunstancia de que el gobierno mexicano consideró que es suficiente hacer frente a la pandemia con las medidas señaladas y no a través de suspender garantías en términos de lo previsto en el artículo 29 constitucional, de manera que "la autoridad pudiera hacer frente a las circunstancias que motivan una declaratoria de estado de excepción, permitiéndole legislar y aplicar administrativamente las propias normas", ${ }^{6}$ como sí ocurrió en países como España o Italia, en donde se impusieron estrictos confinamientos a la población por un tiempo determinado a fin de reducir al máximo la transmisión del virus. En segundo lugar, cabe igualmente que el INAI decidiera suspender sus labores, incluso de manera virtual, dejando con ello a la deriva la protección de derechos fundamentales en la pandemia como es el acceso a la información y la protección de datos; los que se consideran esenciales en un período donde la transparencia e información resulta importante no solo para tomar medidas frente a las circunstancias excepcionales que se viven, sino en general, para poder conocer el desenvolvimiento de la enfermedad y tener certeza de la realidad y gravedad de lo que está ocurriendo.

\section{LA IMPORTANCIA DE UN GOBIERNO ABIERTO Y RESPONSABLE EN ÉPOCA DE LA PANDEMIA Y SU VIGILANCIA POR UN ÓRGANO AUTÓNOMO}

El INAI es un órgano constitucional autónomo encargado de garantizar el cumplimiento de los derechos de acceso a la información pública y protección de datos personales en México, de acuerdo con el artículo $6^{\circ}$, apartado A, fracción VIII de la Constitución mexicana. Entre sus facultades se encuentra la de "dictar los acuerdos necesarios para hacer efectivas sus atribuciones", según lo establece el artículo 33, fracción XX de la Ley Federal de Transparencia y Acceso a la

4 Véase http://dof.gob.mx/nota_detalle.php?codigo $=5590062 \&$ fecha $=20 / 03 / 2020$

5 Véase http://ttp.inifap.gob.mx/regiones/001/CorreoMasivo/2020/CAS/1.1\%20ACT-EXT-PUB-20-03-2020.02. pdf

6 DE SILVA GUTIÉRREZ, Gustavo, "Suspensión de garantías. Análisis del artículo 29 constitucional”, en Cuestiones Constitucionales Revista Mexicana de Derecho Constitucional, núm. 19, julio-diciembre de 2008, México, IIJ-UNAM, p. 70. 
Información Pública. En este sentido, resulta relevante que el 20 de marzo el INAI haya emitido un Acuerdo mediante el cual aprobó diversas medidas para garantizar los derechos de protección de datos y acceso a la información durante la pandemia y entre ellas se decidiera suspender los plazos y términos en todos los trámites y procedimientos de impugnación como son las solicitudes de acceso a la información y el ejercicio de los derechos ARCO (acceso, rectificación, cancelación y oposición), así como los medios de impugnación, procedimientos de investigación y verificación, de imposición de sanciones y denuncias por incumplimiento a las obligaciones de transparencia. ${ }^{7}$ Ante estos hechos, se considera que se deja en vulneración y agravio los derechos de las personas para exigir de las autoridades el conocimiento de la información que resulte de interés general y sea vital para la prevención y el combate a la pandemia, así como el tratamiento de los datos personales, en especial, los sanitarios, que con motivo de su recolección pudieran verse afectados durante esta época.

El acceso a la información pública es esencial en circunstancias extraordinarias como la pandemia, en primer lugar, porque bajo el principio de máxima publicidad establecido en el artículo $6^{\circ}$ constitucional, apartado A, fracción I, "los sujetos obligados deberán documentar todo acto que derive del ejercicio de sus facultades, competencias o funciones". En segundo lugar, el gobierno al emitir decretos de emergencia que le permitan hacer uso de sus facultades discrecionales para hacer frente a la crisis sanitaria podría al mismo tiempo conllevar a un manejo opaco de los recursos no solo económicos sino sanitarios, estadísticos, sociales, etcétera y, en última instancia a la corrupción. En consecuencia, la fiscalización a los sujetos con responsabilidades durante una emergencia sanitaria no debe soslayarse y más aún es importante que se rindan cuentas en todos los sectores.

La máxima publicidad exige, además, que "la información a disposición del público pueda publicarse de tal forma que facilite su uso y comprensión por las personas, asegurando que sea de calidad, veraz, oportuna, actual y confiable" (artículo 7, fracción XVII, segundo párrafo de la Ley Federal de Transparencia y Acceso a la Información Pública). De lo que se puede deducir que no basta que la información se difunda por los medios tradicionales sino que es necesario que su alcance sea mayor, poniéndose a disposición en medios electrónicos o cualquier otro que facilite su comunicación y comprensión. Así también, se exige que la información esté disponible de manera clara y accesible y que se actualice de manera constante y eficaz, exceptuando aquélla que por su naturaleza sea confidencial o reservada y siempre que expresamente sea considerada así por la propia ley. La claridad y accesibilidad de la información también incluye el acceso a internet, por lo que los gobiernos deben asegurar de forma prioritaria un acceso rápido y lo más amplio posible, centrándose en especial en garantizar el acceso a aquéllas personas con acceso limitado o cuando una discapacidad o vulnerabilidad dificulte ese acceso. ${ }^{8}$

7 Véase http://ftp.inifap.gob.mx/regiones/001/CorreoMasivo/2020/CAS/1.1\%20ACT-EXT-PUB-20-03-2020.02. pdf

8 Comunicado de expertos internacionales de NU, CIDH y el Representante para la Libertad de los Medios de Comunicación de la OSCE "Covid-19: los gobiernos deben promover y proteger el acceso a y el flujo libre 
Por su parte, una adecuada protección de datos durante la pandemia implicaría que se está cumpliendo lo estipulado por la ley, pues ella misma ha considerado las circunstancias especiales de recolección de datos. Así, se establece que:

"El responsable no estará obligado a recabar el consentimiento del titular para el tratamiento de sus datos personales en los siguientes casos: VII. Cuando los datos personales sean necesarios para efectuar un tratamiento para la prevención, diagnóstico, la prestación de asistencia sanitaria" (artículo 22, fracción VII de la Ley General de Protección de Datos Personales en Posesión de Sujetos Obligados).

Este precepto es la base para encuadrar la normal recolección de datos que se realice durante una emergencia sanitaria aun sin el consentimiento del titular. En efecto, la ley ha previsto la no recolección del consentimiento del titular en época de la pandemia porque de lo contrario sería lento y poco eficaz, sin embargo, incluso en tales circunstancias los principios de licitud, finalidad, lealtad, calidad, proporcionalidad, información y responsabilidad para la recolección siguen subsistiendo. Así, por citar un ejemplo, se debe atender lo previsto por el principio de finalidad establecido en los artículos 18 y 25 de la misma Ley General, en el sentido de tratar los datos personales que resulten adecuados, relevantes y estrictamente necesarios para la finalidad que justifica su tratamiento, esto es para la prevención, el diagnóstico o la prestación de asistencia sanitaria. De acuerdo con la Agencia Española de Protección de Datos (AEPD) la finalidad del tratamiento de datos personales en el contexto de la pandemia se puede clasificar en: i) control de la cuarentena y distanciamiento social; ii) controles de expansión de la pandemia; iii) controles de uso de cubrebocas y aglomeraciones; y iv) el estudio epidemiológico. ${ }^{9}$ Esto es, que en los casos en que se recabe información personal con otro fin o propósito a los señalados, como podría ser para fines comerciales o de otra naturaleza no estaría justificado por la ley aún bajo el mismo contexto. Otro ejemplo es el principio de lealtad contenido en el artículo 19 de la Ley General, de manera que el responsable no deberá obtener ni tratar los datos a través de medios engañosos y fraudulentos, sino siempre con claridad y fácil comprensión para los titulares.

Diversos mecanismos se encuentran disponibles para los ciudadanos de tal manera que puedan ver efectivos sus derechos, en especial, la labor del INAI como órgano garante se torna relevante. De hecho, la Comisión Interamericana de Derechos Humanos (CIDH) en el marco de la emergencia sanitaria señaló la necesidad de que tales órganos que garantizan el derecho de acceso a la información pública y los sujetos obligados deban otorgar prioridad a las solicitudes de acceso a la información relacionadas con la emergencia de salud pública, especialmente

de información durante la pandemia", consultable en https://www.ohchr.org/SP/NewsEvents/Pages/DisplayNews.aspx? NewsID=25729\&LangID=S

9 Conferencia dictada por Luis de Salvador Carrasco, Coordinador de la Unidad de Evaluación y Estudios Tecnológicos (UEET) de la Agencia Española de Protección de Datos (AEPD), con motivo del Conversatorio Virtual "Protección de Datos Personales: Innovación y Gestión durante y después de la pandemia", organizado por el Departamento de Derecho Internacional de la Secretaría de Asuntos Jurídicos de la OEA, el $1^{\circ}$ de junio de 2020 . 
de la información personal sensible de los pacientes y personas sometidas a exámenes durante la pandemia. ${ }^{10}$ Aún más, ha señalado que en los casos en que los Estados posterguen los plazos de solicitudes de información no relacionadas con la pandemia, deberán fundamentar la negativa, así como establecer un espacio temporal para cumplir la obligación y admitir la apelación de estas resoluciones. ${ }^{11}$ Cuestión que el INAI en un principio ${ }^{12}$ desconoció al establecer la suspensión de los plazos de las solicitudes de acceso a la información y protección de datos, como se señaló en el Acuerdo emitido el 20 de marzo.

En definitiva, tanto la transparencia de información pública como la protección de datos durante la pandemia deben mantener su vigencia y ser respetados por la autoridad conforme a lo previsto por las leyes, pues como ha señalado la AEPD "las consideraciones relacionadas con la protección de datos no deberían utilizarse para obstaculizar o limitar la efectividad de las medidas que adopten las autoridades, especialmente las sanitarias, en la lucha contra la epidemia". ${ }^{13}$ Dicho de otro modo, "lo que no debe permitirse es ignorar los principios y garantías que han de observarse en relación con el derecho fundamental a la protección de datos, ya que no se trata de un derecho impertinente que prohíba sin más hacer cosas, más bien marca el camino de cómo deben hacerse las cosas". ${ }^{14}$

\section{OTROS SECTORES QUE DEBEN SER PROTEGIDOS DURANTE LA PANDEMIA}

Durante la pandemia existen otros sectores relacionados con el acceso a la información y la protección de datos cuya seguridad debe garantizarse igualmente debido a la función que desempeñan. Tal es el caso del trabajo de la prensa y los periodistas en su labor de cubrir la pandemia; de los derechos del consumidor sobre todo con la intensificación de las compras en internet; y el teletrabajo durante la pandemia.

El trabajo de los periodistas por la función que desempeñan de informar a la población y las restricciones a su libertad de expresión es considerado de especial importancia por diversos expertos internacionales. ${ }^{15}$ Los que han señalado

10 Comisión Interamericana de Derechos Humanos, Pandemia y Derechos Humanos en las Américas, Resolución 1/2020, pp. 14 y 15. Se puede consultar en http://oas.org/es/cidh/decisiones/pdf/Resolucion-1-20-es.pdf

11 Ibídem, p. 14.

12 Cabe mencionar que en fecha posterior de 15 de abril el INAI emitió otro Acuerdo para modificar los efectos del Acuerdo de 20 de marzo, en el sentido de reanudar las sesiones del Pleno, mismas que señaló se transmitirán en línea en la página oficial del Instituto y a través de sus redes sociales. Véase http://inicio.ifai.org.mx/ AcuerdosDelPleno/ACT-PUB-15-04-2020.02.pdf

13 Informe 0017/2020 del Gabinete Jurídico de la Agencia Española de Protección de Datos (AEPD) sobre tratamientos de datos resultantes de la actual situación derivada de la extensión del virus Covid-19, disponible en https://www.aepd.es/es/documento/2020-0017.pdf

14 Véase la opinión de José Luis Piñar Mañas, "La protección de datos durante la crisis del coronavirus", delegado de la protección de datos del Consejo General de la Abogacía Española, disponible en https://www. abogacia.es/actualidad/opinion-y-analisis/la-proteccion-de-datos-durante-la-crisis-del-coronavirus/

15 Comunicado de expertos internacionales de NU, CIDH y el Representante para la Libertad de los Medios de Comunicación de la OSCE "Covid-19: los gobiernos deben promover y proteger el acceso a y el flujo libre de información durante la pandemia", op. cit. 
su preocupación por la libertad de expresión de las personas que ejercen el periodismo así como las detenciones arbitrarias de que son objeto en el marco de la cobertura de la pandemia. ${ }^{16}$ Por ello, recomiendan la adopción de medidas positivas adicionales de protección a este grupo, entre las que destacan abstenerse de restringir el trabajo y la circulación de información, bloquear total o parcialmente sitios y medios de comunicación, plataformas o cuentas particulares en internet, etcétera; a su vez que los Estados tienen la obligación de permitirles el acceso a las conferencias de prensa oficiales sin discriminación por línea editorial, pues su papel es fundamental para que la información sea universal y llegue a toda la población. También porque dentro de su labor se hace compatible el cuestionamiento y monitoreo a la autoridad sobre las decisiones que toman, estando mayormente expuestos a un escrutinio y a la crítica pública las declaraciones de los funcionarios con responsabilidades sobre la pandemia. ${ }^{17}$

Otro aspecto que ha adquirido un carácter relevante durante la pandemia son los derechos de los consumidores por internet. En América Latina la pandemia aceleró la adopción de las compras en aplicaciones digitales de hasta el 93\% durante el confinamiento. ${ }^{18}$ Concretamente en México, es un hecho que por las medidas de aislamiento social y las recomendaciones de la autoridad para no salir de casa las personas han recurrido a métodos diversos de consumo como la compra por internet, bien sea para cuestiones tradicionales como compras de videojuegos, películas, música o libros (incrementos de entre $15 \%$ y $60 \%$ ) o para compras de bienes básicos como comida o artículos de higiene y ropa (incrementos de hasta $300 \%) .{ }^{19}$ En el mismo sentido, un estudio realizado por la Asociación Mexicana de Venta Online (AMVO) destacó que en este período de pandemia las categorías que más se han comprado en internet son: comida a domicilio (40\%), moda (30\%), supermercado (28\%), productos para el aseo del hogar $(26 \%)$, y electrónicos $(24 \%){ }^{20}$

Este cambio de hábitos de los consumidores prefiriendo los comercios en internet o ecommerce a los comercios físicos supone también riesgos relacionados con la vulneración y robo de sus datos, en especial los bancarios, domiciliarios y telefónicos, todos ellos considerados información privada. Dejando expuesta dicha información que puede hackearse y posteriormente comercializarse sin el consentimiento de sus titulares. Ante ello, lo más importante es instar a los vendedores a adquirir herramientas de seguridad en sus bases de datos que garanticen la confidencialidad de la información al ofrecer sus productos y servicios, al mismo

\footnotetext{
16 Comisión Interamericana de Derechos Humanos, Pandemia y Derechos Humanos en las Américas, Resolución 1/2020, op. cit., p. 6.

17 Comisión Interamericana de Derechos Humanos, Pandemia y Derechos Humanos en las Américas, Resolución 1/2020, op. cit., p. 13.

18 Véase https://www.amvo.org.mx/wpcontent/uploads/2020/09/AMVO_Estudio4.0_ImpactoCOVID19_ VP\%C3\%BAblica-.pdf

19 Debido a la poca información disponible todavía sobre el consumo en los tiempos de la pandemia se puede ver https://www.forbes.com.mx/el-efecto-de-covid-19-en-el-ecommerce/

20 Véase nuevamente https://www.amvo.org.mx/wpcontent/uploads/2020/09/AMVO_Estudio4.0_ImpactoCOVID19_VP\%C3\%BAblica-.pdf
} 
tiempo que refuercen los mecanismos de acceso. Igualmente resulta importante educar sobre el cuidado de datos para los usuarios con el fin de crear contraseñas seguras e implementar acciones de seguridad en sus dispositivos. Sobre este tema el INAI tiene una gran oportunidad para difundir campañas de prevención y atención con la finalidad de que las personas sean responsables en el cuidado de sus datos, conozcan sus derechos en caso de vulneración o uso indebido y tengan a su disposición los mecanismos para hacerlos valer.

El tercer rubro relativo al teletrabajo merece atención por ser una actividad que se ha implementado de manera reciente y casi improvisada en la pandemia. En este sentido, muchas empresas y la mayoría de universidades públicas y privadas han optado por las clases en línea o por realizar actividades a distancia con el fin de evitar la reunión de personas en espacios pequeños y con ello el contagio masivo. Frente a esta situación, existen recomendaciones de diversa índole para proteger los datos personales cuando se teletrabaja. Ejemplo de lo anterior son las recomendaciones que la AEPD ha emitido en el marco de su campaña de difusión "Protección de Datos y coronavirus", entre las que señala recurrir a proveedores y encargados que ofrezcan soluciones probadas y garantías suficientes para evitar la exposición de datos del personal de la empresa u organización, cuidando que si se accede a información de carácter privado tendrán la consideración de encargados del tratamiento, por lo que se regirán por la ley de protección en la materia debiendo respetar los principios, la duración, la naturaleza y el objeto del tratamiento de datos. ${ }^{21}$

A los usuarios, por su parte, se recomienda también que mantengan actualizados sus dispositivos y sistemas operativos con el fin de garantizar una adecuada protección de sus claves y contraseñas; así como instalar únicamente aplicaciones autorizadas por la organización o empresa y contar con un software antivirus actualizado, entre otras. ${ }^{22}$ En el mismo sentido, el INAI a través de diversas infografías ha alertado a los usuarios de las reuniones virtuales sobre tomar medidas preventivas como leer con atención las políticas de privacidad de los servicios con la finalidad de conocer los datos que pueden recabarse; descargar las versiones más actuales del software disponible para la sesión virtual; evitar asociar la cuenta de correo electrónico o perfil de redes sociales para iniciar sesión en este tipo de servicios, etcétera. ${ }^{23}$

\section{RETOS ACTUALES DEL ACCESO A LA INFORMACIÓN Y PROTECCIÓN DE DATOS EN LA PANDEMIA}

Por último, deben añadirse los retos que representa la pandemia tanto en lo jurídico como en lo social. En lo jurídico, los retos que se enfrentan son, en primer lugar, la creación e implementación de una cultura transversal de transparencia y

\footnotetext{
21 Para mayor información consúltese https://www.aepd.es/sites/default/files/2020-04/nota-tecnica-protegerdatos-teletrabajo.pdf

22 Véase https://www.aepd.es/sites/default/files/2020-04/nota-tecnica-proteger-datos-teletrabajo.pdf

23 Puede consultarse en el siguiente enlace https://micrositios.inai.org.mx/covid-19/?page _id=974
} 
rendición de cuentas en todos los órganos de gobierno. En este sentido, es necesario que el INAI como órgano garante a nivel nacional y como parte integrante fundamental del Sistema Nacional de Transparencia inicie e impulse esa cultura, con el fin de establecer junto a los demás órganos de transparencia en las Entidades Federativas políticas de transparencia proactiva, así como políticas de protección de datos de diversos grupos entre los que se podrían cometer mayores abusos como son las personas con discapacidad, personas indígenas y otros. En el rubro de la protección de datos cabe señalar el tratamiento de datos en el ámbito laboral derivado de la actual situación de pandemia, el cual obliga de igual manera a emitir informes o guías para conocer la información que debe proporcionarse.

En lo social, el INAI tiene el compromiso de educar en transparencia y acceso a la información pública impulsando guías para los ciudadanos a fin de combatir de forma transparente la desinformación que circula respecto de la pandemia, ${ }^{24}$ pues puede conducir a "problemas de salud, pánico y desorden". ${ }^{25} \mathrm{~A}$ este respecto es fundamental que las noticias falsas puedan contrastarse con información científica, apoyándose precisamente de los medios de información tradicionales y virtuales. En consecuencia, a lo que se puede concluir de lo expresado anteriormente es que es necesario generar confianza en la población a través de la implementación de campañas de información sobre el virus. Pues como han expresado expertos internacionales "la salud humana no depende exclusivamente del acceso inmediato a atención médica. También depende del acceso a la información precisa sobre la naturaleza de las amenazas y sobre los medios para protegerse a uno mismo, a nuestra familia y a nuestra comunidad". ${ }^{26}$ En general, es importante conocer y discutir sobre las medidas que el gobierno está tomando para frenar la pandemia, hacer cuestionamientos y debates con los expertos en salud, en educación y con cualquiera involucrado en la toma de decisiones.

\section{CONCLUSIONES}

El acceso a la información y la protección de datos personales son dos derechos que adquieren especial relevancia en la época de la pandemia. Por una parte, las personas deben conocer el tratamiento que se le está dando a la enfermedad, pero también el impacto de las medidas que toma el gobierno ya sea en infraestructura, en compra de medicamentos y, en general, al hacer uso de cualquier gasto que tenga como finalidad frenar la epidemia. El principio de máxima publicidad contenido en la Constitución mexicana considera que la información pública debe ser, entre otras cuestiones, clara, fluida y actualizada y los límites a

24 Comisión Interamericana de Derechos Humanos, Pandemia y Derechos Humanos en las Américas, Resolución 1/2020, op. cit., p. 13.

25 Comunicado de expertos internacionales de NU, CIDH y el Representante para la Libertad de los Medios de Comunicación de la OSCE "Covid- 19: los gobiernos deben promover y proteger el acceso a y el flujo libre de información durante la pandemia", op. cit.

26

Ídem. 
ella solo pueden estar establecidos en las mismas leyes. La protección de los datos implica poder conocer el tratamiento que se les da a los mismos, más si son recolectados con motivo de la pandemia. Las personas deben poder exigir, al mismo tiempo, que sus datos sean tratados conforme a la finalidad, que no se comercialicen sin su consentimiento y que en caso de vulneración puedan acceder a los mecanismos de tutela y protección.

El papel del INAI y de los demás órganos garantes de las Entidades Federativas en época de la pandemia se torna relevante porque ellos pueden dictar lineamientos para promover la toma de decisiones gubernamentales de manera informada, transparente y clara. Más aún, se deben seguir atendiendo todas las solicitudes de acceso a la información, dando prioridad a aquéllas relacionadas con la emergencia sanitaria pero sin descuidar y dando espacio posterior para resolver aquellas secundarias, tal y como lo ha señalado la $\mathrm{CIDH}$.

También es importante que se consideren otros aspectos como el rol que desempeñan los periodistas en esta época, pues "el periodismo cumple una función crucial ante un momento de emergencia de salud pública, en especial cuando su objetivo es proporcionar al público información fundamental y supervisar las medidas gubernamentales". ${ }^{27}$ En este sentido, es importante que se tomen medidas para su protección, evitando en todo momento la censura. En el mismo sentido las compras en internet y el teletrabajo, que han emergido como consecuencia del aislamiento y la sana distancia y con ello nuevos y mayores riesgos como el robo de datos, la suplantación de identidad, así como otros delitos cibernéticos relacionados con los menores de edad.

\section{BIBLIOGRAFÍA}

Acuerdo emitido por el INAI mediante el cual se aprueban diversas medidas para garantizar los derechos de protección de datos personales y acceso a la información, ante la situación de contingencia generada por el denominado virus covid-19 publicado en el Diario Oficial de la Federación http:// ftp.inifap.gob.mx/regiones/001/CorreoMasivo/2020/CAS/1.1\%20ACTEXTPUB-20-03-2020.02.pdf

Acuerdo número 03/03/20 por el que se suspenden los plazos y términos relacionados con los trámites y procedimientos administrativos que se llevan a cabo ante la Secretaría de Educación Pública, publicado en el Diario Oficial de la Federación http://dof.gob.mx/nota_detalle.php?codigo $=5590062 \&$ fecha $=$ 20/03/2020

Acuerdo por el que se declara como emergencia sanitaria por causa de fuerza mayor, a la epidemia de enfermedad generada por el virus SARS-CoV2 (COVID-19) del Consejo de Salubridad General publicado en el Diario Oficial de la Federación https://dof.gob.mx/2020/CSG/CSG_300320_VES.pdf

Acuerdo por el que se establecen acciones extraordinarias para atender la emergencia sanitaria generada por el virus SARS-CoV2 de la Secretaría de Salud,

27 Ídem. 
publicado en el Diario Oficial de la Federación http://dof.gob.mx/nota_deta1le.php? codigo $=5590914 \&$ fecha $=31 / 03 / 2020$

Acuerdo mediante el cual se modifican y adicionan los diversos Act-ExtPub/20/03/2020.02 y Act-Ext-Pub/20/03/2020.04, en el sentido de ampliar sus efectos al 30 de abril del año en curso inclusive, con motivo del acuerdo emitido por la Secretaría de Salud, por el que se establecen acciones extraordinarias para atender la emergencia sanitaria generada por el virus sars-cov2, publicado en la edición vespertina del Diario Oficial de la Federación en http://inicio. ifai.org.mx/AcuerdosDelPleno/ACT-PUB-15-04-2020.02.pdf

Comisión Interamericana de Derechos Humanos, Pandemia y Derechos Humanos en las Américas, Resolución 1/2020. http://oas.org/es/cidh/decisiones/pdf/ Resolucion-1-20-es.pdf

Comunicado de expertos internacionales Covid- 19: los gobiernos deben promover y proteger el acceso a y el flujo libre de información durante la pandemia, consultable en https:/www.ohchr.org/SP/NewsEvents/Pages/DisplayNews. aspx? NewsID $=25729 \&$ LangID $=\mathrm{S}$

Conferencia dictada por Luis de Salvador Carrasco, Coordinador de la Unidad de Evaluación y Estudios Tecnológicos (UEET) de la Agencia Española de Protección de Datos (AEPD), con motivo del Conversatorio Virtual "Protección de Datos Personales: Innovación y Gestión durante y después de la pandemia”, organizado por el Departamento de Derecho Internacional de la Secretaría de Asuntos Jurídicos de la OEA, el $1^{\text {o }}$ de junio de 2020.

Datos personales seguros covid 19 publicado por el INAI https://micrositios.inai. org.mx/covid-19/?page_id=974

DE SILVA GUTIÉRREZ, Gustavo, "Suspensión de garantías. Análisis del artículo 29 constitucional", en Cuestiones Constitucionales Revista Mexicana de Derecho Constitucional, núm. 19, julio-diciembre de 2008, México, IIJ-UNAM. Estudio realizado por la Asociación Mexicana de Venta Online sobre la tendencia de compra por internet durante la pandemia https://www.amvo.org. $\mathrm{mx} /$ wpcontent/uploads/2020/09/AMVO_Estudio4.0_ImpactoCOVID19 VP\%C3\%BAblica-.pdf

Informe 0017/2020 del Gabinete Jurídico de la Agencia Española de Protección de Datos (AEPD) sobre tratamientos de datos resultantes de la actual situación derivada de la extensión del virus Covid-19, disponible en https://www.aepd. es/es/documento/2020-0017.pdf

PIÑAR MAÑAS, José Luis, "La protección de datos durante la crisis del coronavirus", delegado de la protección de datos del Consejo General de la Abogacía Española, disponible en https://www.abogacia.es/actualidad/opinion-y-analisis/la-proteccion-de-datos-durante-la-crisis-del-coronavirus

Recomendaciones para proteger los datos personales en situaciones de movilidad y teletrabajo emitidas por la Agencia Española de Protección de Datos Personales de España https:/www.aepd.es/sites/default/files/2020-04/nota-tecnicaproteger-datos-teletrabajo.pdf

Sitio de noticias Forbes https://www.forbes.com.mx/el-efecto-de-covid-19-en-elecommerce/ 